\title{
Documenting the Diffusion of the 2016 French Nuit Debout
}

\section{Social and Behavioural Sciences}

\author{
Stéphane Baciocchi \\ École des Hautes Études en Sciences Sociales, Paris, France \\ baciocch@ehess.fr
}

\author{
Laurent Beauguitte \\ UMR Géographie-cités, Centre National de la Recherche Scientifique \\ (CNRs), Paris, France \\ laurent.beauguitte@cnrs.fr
}

\author{
Pierre Blavier \\ CNRs, Villeneuve d'Ascq Cedex, France \\ pierre.blavier@univ-lille.fr
}

\author{
Nicolas Lambert \\ RiATE, CNRs, Paris, France \\ nicolas.lambert@cnrs.fr
}

\begin{abstract}
In the spring of 2016, France saw a major social movement, with strikes and demonstrations, and a new form of protest, the Nuit Debout. Following the Occupy Wall Street and Los Indignados models, open air assemblies started in Paris on March 31 and then spread throughout France and abroad. The dataset presented here provides the exhaustive list of Nuit Debout gatherings that took place in France in April 2016 and an estimation of their audience. The data was gathered by a small multidisciplinary team (geographers, historian and sociologist) who consulted three main sources: a wiki created by the Nuit Debout movement, Facebook pages and groups created by local assemblies, and the regional press. Combining these sources made it possible to identify 1300 assemblies that took place in 215 different locations. The dataset available online is provided with an R script that generates a dynamic map of the Nuit Debout diffusion.

(C) STÉPHANE BACIOCCHI, LAURENT BEAUgUitTE, PIERRE BLAVIER \& NiCOLAS LAMBERT, 2019 DOI:10.1163/24523666-00401005 This is an open access article distributed under the terms of the prevailing CC-BY license at the time of publication.
\end{abstract}




\section{Keywords}

Nuit Debout - social movement - France - geography - protest - R script - social mobilization

- Related data set "Nuit Debout" with Dor https://doi.org/10.5281/zenodo .3056000 in repository "Zenodo"

\section{Introduction}

The spring of 2016 saw a major social protest in France against a law that modified the French labor code. This protest triggered strikes and street demonstrations, but also a more innovative form of protest in the French political landscape called Nuit Debout (Up All Night). Its most visible form consisted of open-air assemblies, open to anyone, following the model of Occupy Wall Street in the USA and Los indignados in Spain to a certain extent. The main difference is that the latter protests occupied public squares whereas the Nuit Debout happened only in the evenings, because the police prevented the crowds from occupying during the night. This protest occurred after the terrorist attacks of November 2015 in Paris and one year before the presidential and legislative elections coming in June 2017.

This paper, and the dataset it presents, deals with the geographical diffusion of the Nuit Debout movement in France. The first gathering occurred in Paris, on Thursday, March 31, 2016, but it did not take long for others to appear in a few major cities and then throughout France. Some even took place abroad, but their number remained limited and we restrict ourselves henceforth to the French ones.

Most media and academics focused on the Parisian Nuit Debout protests ("Nuit debout", 2016; Smaoui, 2018; Gérard \& Bertina, 2018), skirting the question of whether or not the movement was able to extend beyond Paris. Obviously, this issue is crucial, given that the French capital city is unique in terms of the sociological features of its population in comparison with the rest of France: over-representation of managers, of the cultural sector, rising gentrification in formerly lower-income areas, etc. In our opinion, this geographical restriction does not make it possible to correctly assess the order of magnitude and gain a full picture of this movement. However, it is hard to blame these journalists, French intellectuals and "experts" for their Paris-centric perspective, since until now, there has not been any systematic or rigorous collection 
of data to document what was happening in other locations. Such fluid events are typically difficult to document and to qualify, in terms of order of magnitude, regarding the number of participants, their characteristics, its channels of diffusion, etc. By carefully documenting the Nuit Debout movement beyond the Parisian Place de la République, the idea of our dataset is to give further insights on what the Nuit Debout movement really was, as this form of protest (Tilly, 1986, 2003) has remained rare in the previous decades in France.

Therefore, it is this precise gap that we propose to fulfill empirically. We aimed at providing as exhaustive a census as possible for these assemblies, and estimations of the number of participants. This issue of crowd counting has already been the subject of significant contributions. Jacobs's Method is the most common technique for counting crowds at protests and rallies, after 1960 s Berkeley journalism professor, Herbert Jacobs. It involves dividing the area occupied by a crowd into sections, determining an average number of people in each section, and multiplying by the number of sections occupied. In The myth of the madding crowd (1991), Clark McPhail reassesses the historical literature on crowd analysis, and presents various manners to count (McPhail \& McCarthy, 2004). More recently, the project Crowdcount (http://crowdcount $. \mathrm{org} /$ ) proposed a solution to record crowd size events in real-time with a smartphone application. None of these methods was implementable here, because it was impossible to attend all meetings and there is no systematic video or internet account for each of them.

We have documented all Nuit Debout gatherings that occurred in France in April 2016. This month-long time delimitation is due to various reasons. First, most instances of the Nuit Debout emerged in this month. Some appeared later, in May or June, but their number remains very limited (15 out of 253). Second, they were most active during this month and most of them declined afterwards. Third, we were interested more in the diffusion of the movement, rather than in its duration. Our data does not allow us to identify any straightforward diffusion path, but does show that the Nuit Debout movement did indeed extend widely beyond Paris. It was very idiosyncratic and very diverse across time and space.

The first thing that we shall do is to present how we collected information on all Nuit Debout gatherings, by filling the dataset with the dates of the gatherings and writing a harmonized note for each of them. ${ }^{1}$ We relied on information found on the internet, drawn from three main sources. First, the wiki

1 These notices, written in French, and not fully harmonized, cannot be made available in a short-term perspective. Complementary work, involving interviews, is planned in the following years. 
established by the movement itself (https://wiki.nuitdebout.fr/wiki/Villes/), ${ }^{2}$ which counts 248 municipalities where it is supposed that at least one Nuit Debout protest took place. We consider it as a sort of census of the movement but we were also able to find some Nuit Debout occurrences that were not present on this wiki. Secondly, we looked at websites and Facebook pages created by activists. Lastly, we used local newspapers, as this movement created a large amount of interest from the media at both regional and national levels. In some cases, we used our fieldnotes, as some of us made direct and participant observations of this movement. Obviously, none of these sources is $100 \%$ reliable, but when considered together they provide a good level of accuracy on the Nuit Debout movement and the media attention that it created. The main difficulty is that the relevant aspects to understand such a social movement are not known a priori. These have to be explored along the way, and it takes time to gain a better understanding of this movement. All this documentation led to various results regarding the diffusion of the movement through space and time, which we present briefly in a second part. The dataset provides an exhaustive list of Nuit Debout assemblies that took place in France with the following information: city name, alliance and source used. A shapefile and an annotated $\mathrm{R}$ program allowing these meetings to be mapped are also provided.

\section{Methods of Data Gathering and Analysis}

- Nuit Debout deposited at Zenodo - DoI:10.5281/zenodo.305600o

- Nuit Debout

- The script to reproduce this analysis - URL: https://www.nakala.fr/ data/11280/292348ab

- Temporal coverage: 31 March - 30 April 2016

Collaborative work was required in order to gather information, as three digital sources were explored. Two engineers, one geographer and one sociologist worked together for several months; all of them participated in the Nuit Debout movement, three in Paris (Place de la République and several other Nuit Debout locations in Paris and its suburbs), and one in Melun (Île-de-France).

\subsection{First Source: Nuit Debout Wiki Pages}

Our first step was to explore the wiki created by the movement itself. Overall, it contains 411 cities, of which 253 are in Metropolitan France. Among these

2 The Nuit Debout wiki is still available via http://web.archive.org. 
latter, 15 instances occurred later than April and for 17, we have found no other indication of their existence than their mention in the wiki. Therefore, our definitive sample contains 221 municipalities.

Sometimes, the accounts are very thorough, providing many details, as in the case of Calais. Matthieu Marsan-Bacheré was a zealous clerk of the assembly in this city, producing records of the number of participants for the whole month of April. He made clear the difficulties of estimating the number of participants and the fluctuations from one day to another, in terms of quantitative participation but also regarding the atmosphere of the gathering. We also have thorough records in the cases of Tulle, Grenoble, Le-Puy-en-Velay and several other cities.

However, such cases are not so numerous. Most of the wiki pages provide only part of the information (Guingamp, Istres and La Ciotat, among others), while some Nuit Debout occurrences do not appear on this wiki (Bar-sur-Aube, Château-Thierry, Creil, etc.). We supplemented this first source of information with others, which are sometimes mentioned in the wiki (Twitter and most of all Facebook).

\subsection{Second Source: Facebook, Twitter and Websites}

We systematically explored major social networks (Facebook, Twitter) and websites or blogs (often indicated in the wiki). It is worth noting that, by the time our data collection process started, one year after the beginning of the Nuit Debout movement in March 2016 (summer 2017), websites and blogs have disappeared (8 out of 17) more often than Facebook page and Twitter accounts. Scrolling down Facebook pages is tedious because of the repetition of slogans and talkative exchanges, but it is also very useful to give 1) an idea of the beginning of the assembly thanks to the date of the first post 2) a quantitative estimation of the amount of (online) support, and 3) a collection of meaningful comments on the events that took place. It also helped to identify media coverage posted on Facebook walls. While the Parisian Nuit Debout protest focused a lot on the free and open source, collaborative wiki platform, most Nuit Debout gatherings used the commercial and private social network site Facebook: using the wiki supposed some supplementary skills and did not allow interactions.

\subsection{Third Source: Local Media Coverage}

It is very impressive to note that around $80 \%$ of the Nuit Debout meetings were covered by at least one mention in any local media, either press, associative and/or militant blogs (Bondyblog, Révolution Permanente, etc.), or public TV 
and radio websites like France 3 or France Bleu. Daily newspapers published articles for many of the first assemblies. We found no fewer than 170 news titles, the most frequent of which were Ouest France (2o Nuit Debout municipalities in Western France), Le Parisien (17), Le Dauphiné libéré (13, Southern France), La Dépêche du midi (13, Southern France), Sud-Ouest (8) and La Voix du Nord (7).

These articles about the first Nuit Debout gatherings in each municipality are rather short and follow a common descriptive structure: they remind the reader of the Parisian event, present a photograph of the local assembly, estimate the number of people, mention the date, give the floor to some participants (most often initiators of the gathering), and say some words to qualify the atmosphere (relationship to authorities). This final aspect is important as the Parisian Nuit Debout protest faced several troubles with the police force. Several political leaders asked for its prohibition.

\section{4. $\quad$ Notes, Files and Dataset}

Using these three sources, we first wrote a qualitative note about each Nuit Debout gathering with these basic details:

- which one of us wrote the note, and when;

- the date of the first post in the Facebook page or group (if it exists);

- photos from the local press coverage and counts of the number of people;

- other remarkable features, especially links with other movements (trade unions, political parties, other Nuit Debout gatherings, etc.) and a rough sketch of who the initiators were.

The dataset created from these notes provides the following information:

- Id: unique numerical code for each assembly;

- Id_NdB: name of the municipality where the Nuit Debout gathering took place - code in the Parisian case where 5 different Nuit Debout locations appeared;

- Date: format Year-Month-Day;

- Address: precise location of the Nuit Debout gathering;

- INSEECode: official geographical code of the municipality;

- Latitude and longitude WGS 84 reference;

- Audience_photo: number of participants according to picture of the assembly;

- Audience_Internal_recoded: number of participants according to internal source (wiki, Facebook, etc.) of the Nuit Debout gathering. When a range was given ("2o to 30 persons"), we took the mean of the two numbers;

- Audience_External_recoded: number of participants according to external sources. When a range was given ("2o to 30 persons"), we took the mean of the two numbers; 
- Source: the order of the source follows the order of audience estimation;

- Projection: when a film projection was organized, we indicate it, as it can explain the larger audience of this specific Nuit Debout gathering (see, for example, Aix-en-Provence or Béziers).

It is worth noting that we were not able to find any estimation of the audience for only 17 of the 221 cases. With regard to the largest cities (Paris, Lyon), giving an estimation of the participants on a daily basis is nearly impossible because of the size (see Fig. 1) and the turnover flows of people going in and out. In Paris, the audience ranged from several hundreds (300 to 400 persons on rainy days with no external events such as a demonstration) to several thousands. Hence the slogan "nous sommes des milliers" ("we are thousands").

In Lyon (the second largest city in France), numbers ranged from a hundred to two or three thousand people depending on the context. We just gave a few estimations taken in the press coverage for these two cities. It must also be mentioned that we only considered assemblies naming themselves Nuit Debout: preparatory meetings are not taken into account, nor are spontaneous meetings. In Lyon, open air assemblies took place from March 31 until April 4 but the assembly only decided to call itself Nuit Debout on April 5 .

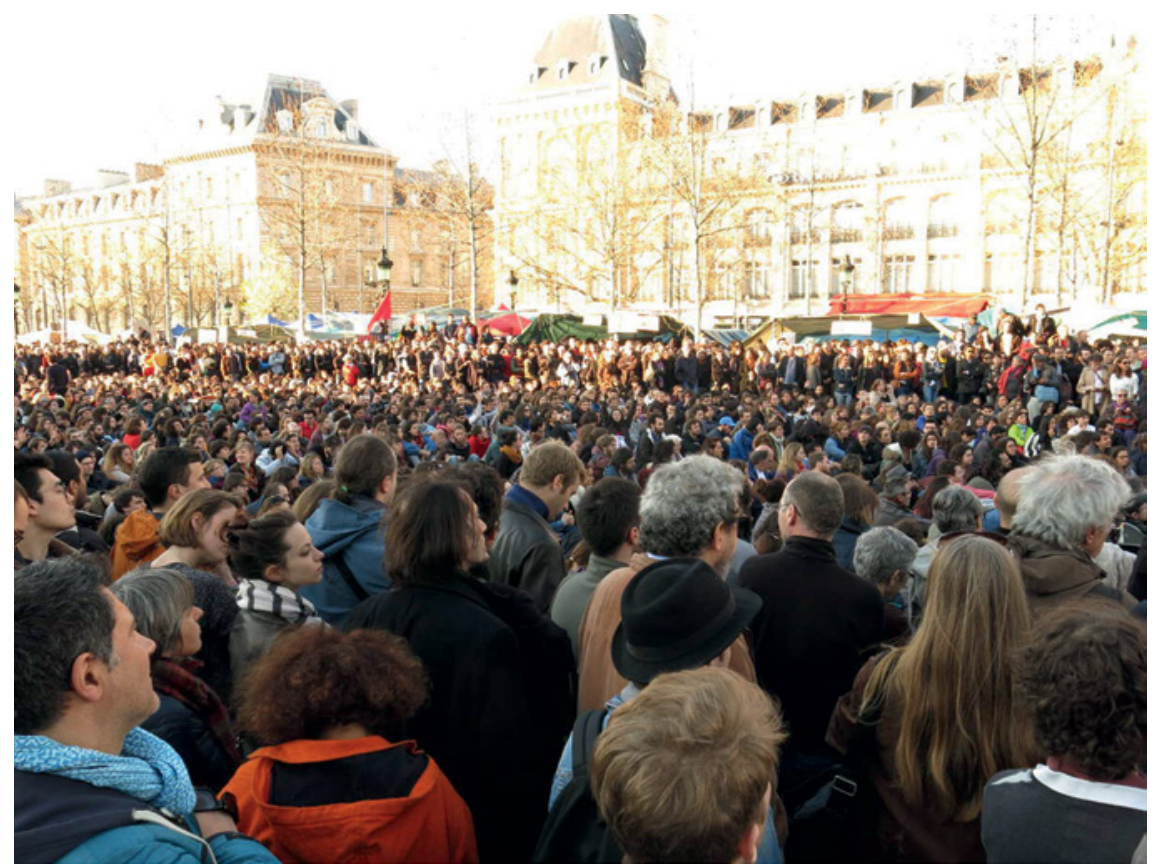

FIGURE 1 Hardly countable crowd at the Nuit Debout in the Place de la République. PIERRE BLAVIER, SUNDAY 17/04/2016 


\section{Geographical and Time Spread of the Nuit Debout Movement}

Figure 2 presents the evolution of the number of Nuit Debout assemblies across the month of April 2016. They remained limited during the first week, but then took off during the weekend of April 8-10, and on every Friday and Saturday. The number of gatherings reached a peak on Saturday, April 23, and decreased very slightly afterwards. This decreasing trend was confirmed in May, as can be seen for the Nuit Debout gatherings in Paris and its suburbs (Beauguitte \& Lambert, 2018).

As expected, the higher the city ranks in the hierarchy regarding its population census, the higher chance there was to see a Nuit Debout protest occurring at the beginning of the period. The only exception concerns cities located near a more central one - Villeurbanne near Lyon, Roubaix and Tourcoing near Lille, etc. But 17 out of the 26 first-week Nuit Debout gatherings (from Thursday, March 31 to Thursday, April 7) occurred in the biggest cities of the country. Seven of them are among the ten most highly populated French cities (Paris, Marseille, Lyon, Toulouse, Nantes, Montpellier, Strasbourg - only Nice, Bordeaux and Lille are missing), four among the top 20 (Rennes, Le Havre, SaintÉtienne, Angers), and six among the 47 French cities with more than 100000 inhabitants (Amiens, Brest, Le Mans, Orléans, and Tours).

However, explaining why it happens here and not there, and why some Nuit Debout assemblies succeeded in gathering a decent audience for several weeks is harder. Local configurations play a major role, as well as the mix of

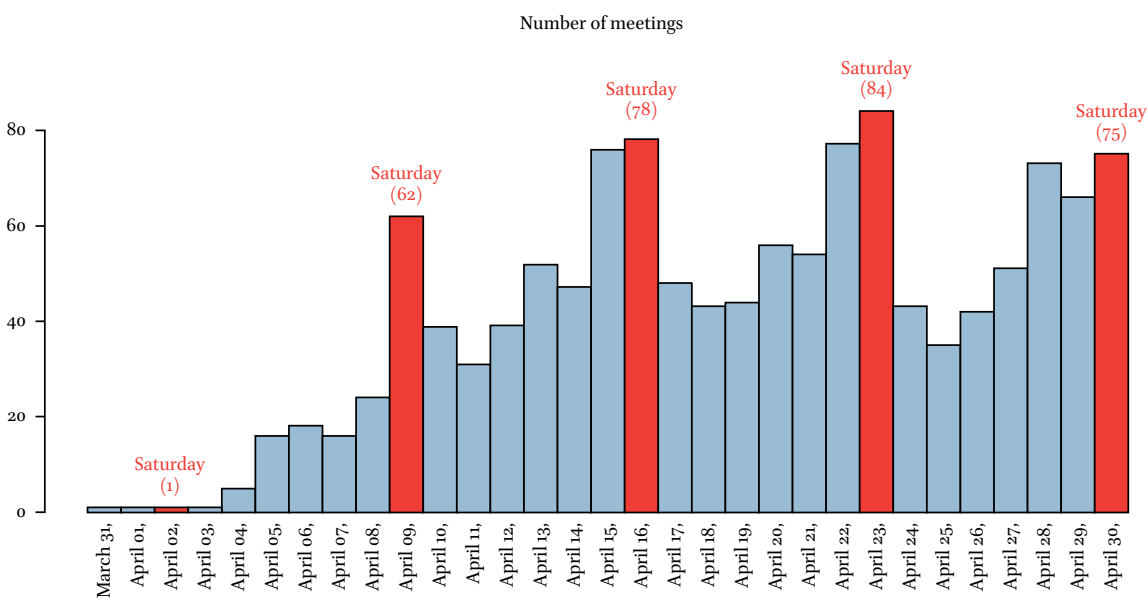

FIGURE 2 Diffusion across time of the Nuit Debout movement in France. How to read: On Saturday, April 9, 2016, 62 Nuit Debout gatherings took place. 


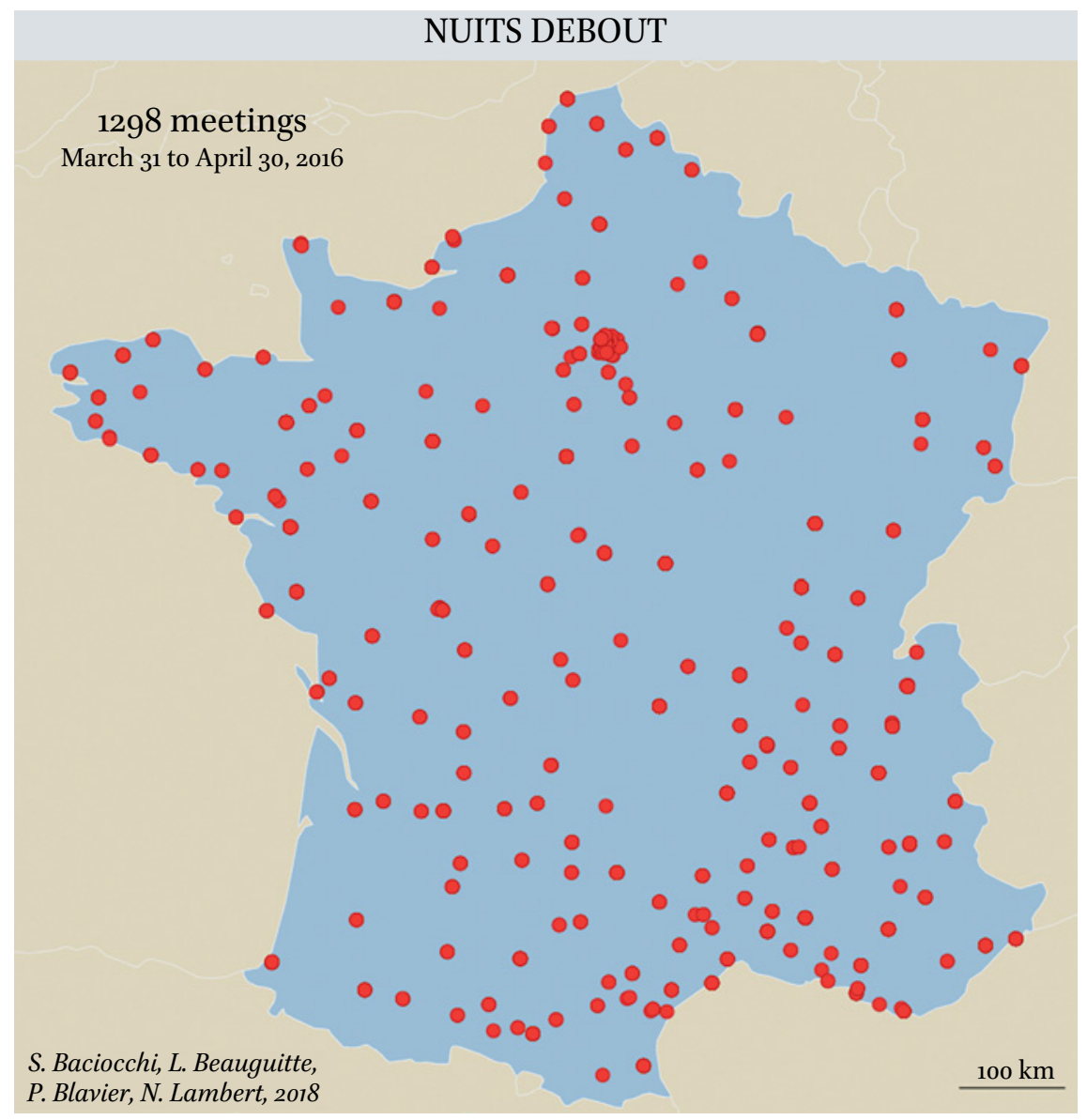

FIGURE 3 Nuit Debout locations (April 2016), summary map

individual militant trajectories, local support from organizations, and the regional and local political context. Our dataset gives opportunities for searching patterns and anomalies but is so far one more aid to understand what happened in France in spring 2016. Nuit debout was far from being limited to Paris.

\section{References}

Beauguitte, L. \& Lambert, N. (2018, October 10). La diffusion spatiale d'une innovation politique. Les Nuits debout d'Île-de-France. Retrieved from https://www .metropolitiques.eu/Les-Nuits-debout-en-Ile-de-France-diffusion-spatiale-d-une -innovation-politique.html. 
Gérard, V. \& Bertina, A. (2018). Occupy la République. Place de la République, Paris. In Collectif, Le livre des places (pp. 239-264). Paris: Inculte.

Nuit debout et notre monde. (2016). Les Temps Modernes, 5(691).

McPhail, C. (1991). The myth of the madding crowd, New York: Adline de Gruyter.

McPhail, C. \& McCarthy, J. (2004). "Who counts and how: estimating the size of protests". Contexts, 3(3), 12-18.

Smaoui, S. (2018). Faites places. Novices en lutte. Paris: Textuel.

Tilly, C. (1986). La France conteste: de 1600 à nos jours. Paris: Fayard.

Tilly, C. (2003). Contention over space and place. Mobilization: An International Quarterly, 8(2), 221-225. 